\title{
The internal structure of English transitive sentences
}

\author{
ROBERTA CORRIGAN \\ University of Wisconsin-Milwaukee, Milwaukee, Wisconsin
}

\begin{abstract}
A major question in psychology is whether the same mechanisms are required for language learning and processing as for other cognitive tasks. A substantial body of literature has shown that natural categories are organized around a prototype, with other category members resembling the prototype to a greater or lesser amount based on the degree of shared properties. In order to investigate whether the prototype notion could be extended to linguistic phenomena, adult students $(N=148)$ rated 512 sentences on a 7-point scale as to their goodness of fit to the category English transitive sentence. Sentences differed in the animacy of their actors and patients, the noun pairs used as actor/patient exemplars, and the hypothesized prototypicality of their verbs. Each of the identified factors showed the spread in rankings across different exemplars that is typical of other natural categories, but the factors interacted with each other in complex ways to determine the overall ranking of the sentence. Not all sentences were equally representative of the category English transitive sentence. In general, sentences with animate actors, high-prototypicality verbs, and animate patients were the most prototypical, followed closely by sentences with animate actors, high-prototypicality verbs, and inanimate patients. Results were consistent with the suggestion that language and other types of cognitive tasks require the same basic processes and structures.
\end{abstract}

There is substantial disagreement in the cognitive psychology literature about the relationship between language and cognition. On the one hand, some psychologists, such as Anderson (1983), argue that the same mechanisms are required for language learning and processing as for any other cognitive tasks. On the other hand, some researchers, such as Fodor (1983) and Chomsky (1983), maintain that language is a unique system requiring separate cognitive faculties and processes.

There are a variety of research strategies for addressing the issue of relationships between cognition and language. One method is to demonstrate that problems in both the language and cognitive domains require solutions that are structurally similar (Bates \& Snyder, 1982). This is the approach that Anderson (1983) used to show that the same "computational architecture," given different sets of experiences, can account for language learning, geometry problem solving, and computer programming.

One of the most basic human cognitive processes is the ability to classify or categorize exemplars into concepts. Categorization is essential to cognition because it provides a means for recognizing familiar information, assimilating new information, and distinguishing among properties, objects, and events (Bornstein, 1984). It has been suggested that a fundamental property of grammar is its categoriality; that is, it contains a set of rules that specify how categories are formed out of other categories (Hop-

This research was supported in part by a sabbatical leave from the University of Wisconsin System and by NIMH Grant No. MSMA 1 R03 MH40433-01A1. Special thanks to John Surber for careful reviews of earlier drafts of this paper. Reprint requests should be sent to the author at the Department of Educational Psychology, University of Wisconsin-Milwaukee, Milwaukee, WI 53201. per \& Thompson, 1984). One central mechanism involved in categorization appears to be schema or prototype formation. The current paper investigates whether the mechanisms that operate in the categorization of exemplars in natural categories are structurally similar to those that operate to organize language in memory. The first section of this introduction reviews research on the internal structure of natural object categories; the second section reviews speculations about how this same type of organization might be applied to linguistic categories.

\section{Categorization of Natural Objects}

The traditional view of categories is that they have necessary and sufficient conditions for membership. Within this view, exemplified by laboratory conceptlearning experiments, an item (e.g., red triangle) is either a member of a category or it is not; that is, it either has the discrete attributes (color and shape) that define it as a member of the category or it does not. All members of a category are logically equivalent.

A contrasting view of category structure is that the properties or features of a concept are characteristic or probable rather than all-or-none (see Medin \& E. Smith, 1984; Mervis, 1980; Mervis \& Rosch, 1981; E. Smith \& Medin, 1981, for reviews of both approaches). Evidence that cognitive categorization is based on representativeness rather than formal class logic involving criterial attributes has come largely from work on object and perceptual concepts, such as color terms (Rosch, 1973, 1975), furniture, or animals (Carey, 1982; Rosch \& Mervis, 1975; Rosch, Mervis, Gray, Johnson, \& BoyesBraem, 1976). In a typical experiment, subjects are asked to make judgments about how good or poor a member 
each exemplar is of its category (Rosch, 1973). Subjects consistently discriminate among exemplars of a category, judging some members to be better exemplars than others. For example, Rosch (1973) found that an apple was consistently judged to be a better fruit than was an olive. Substantial agreement among subjects occurs for exemplars that are very good or very poor category members, whereas there is substantial disagreement among subjects for items with intermediate degrees of membership (McClosky \& Glucksburg, 1978).

Work on common objects has shown that better members (prototypes) of a category are exemplars that are most similar to other category members and most distinct from contrasting categories; they are the most salient members. There is a basic level of reference for classification that is preferred psychologically and linguistically over either more general superordinate or more specific subordinate categories. In a class-inclusion hierarchy (e.g., animal, dog, German shepherd), basic-level categories (dog) function as the prototype, containing a large number of common features within the class (German shepherds and collies share many features) and little overlap among contrasting classes (dogs, birds, and snakes do not share many features). On the other hand, superordinate classes have little feature overlap either with contrasting classes (animals vs. plants) or within the class (birds vs. frogs), whereas subordinate classes have much overlap both within and among categories (Rosch et al., 1976).

Object categories at all levels are decomposable into attributes, such as color. One type of attribute is called a "part." A part is a portion of an object that can be described with a "has a" relationship. For example, in the sentence " a dog has a tail," the tail is part of the dog. This contrasts with other attributes such as "brown," which can be described with an "is" relationship ("The dog is brown'). The proportion of parts that subjects list as attributes can be used to distinguish between superordinate, basic, and subordinate categories. The majority of attributes listed for a category at the basic level are parts. Different basic-level categories (dog and bird) share some attributes (e.g., eats, moves) and differ on parts (four legs vs. wings). Different subordinate categories belonging to the same basic level share parts (all cats have four legs) and differ on other attributes (some are white, some are black). Characteristics of parts are used to distinguish contrasting subordinates (e.g., white fur vs. black fur; Tversky \& Hemenway, 1984).

The features of natural objects occur not in isolation, but rather in clusters. Certain attributes tend to co-occur with others, and these correlated attributes are more salient than would be predicted on the basis of the salience of each attribute alone (Mervis, Medin, \& Rosch, 1984). Correlated attributes are used as one basis of classification, because they allow one to predict attributes from other attributes and, thus, they provide within-category structure (Medin, 1983).

Recently, researchers have begun to extend the probabilistic approach to nonobject domains, such as psy- chiatric categories (Cantor, Smith, French, \& Mezzich, 1980), personality traits (Cantor \& Mischel, 1979), and environmental scenes (Tversky \& Hemenway, 1983). Because the work on nonobject concepts is in its early phases, one major purpose of the research has been to determine in what respects these more complex concepts are similar to or different from simpler object concepts. One possible unifying explanation leading toward a general theory of category structure in both object domains and nonobject domains (such as scenes and events) is the possibility that categories of both types can be decomposed into parts (Tversky \& Hemenway, 1984).

\section{Parallel Categorization Processes in Language}

If sentences are comparable to other object categories, one would expect them to be composed of simpler parts and attributes that are themselves composed of attributes and are organized around prototypes. Transitive sentences have actors, verbs, and patients, which are their major parts. Characteristics of the parts (e.g., an actor is animate or inanimate) should be useful in distinguishing contrasting subordinate categories. Indeed, arguments have been made in the literature that both sentences and the syntactic-semantic categories within sentences are organized around prototypical exemplars (Bates \& MacWhinney, 1982; deVilliers, 1980; Lakoff, 1977; Schlesinger, 1982; Talmy, 1977).

Hypothesized attributes of prototypical sentences. At the sentence level, Slobin and Bever (1982) argued that the simple, active, declarative sentence is the prototypical sentence in any language. Slobin (1981) further argued that the prototypical sentence contains an animate agent who intentionally brings about a physical and perceptible change in the location or state of an inanimate patient by means of direct body contact. This canonical sentence schema initially determines which input strings children analyze and which they ignore. Later, children extend their schemas to include sentences that are nonprototypical, but that are still allowable within a given language. Slobin and Bever do not address whether or not simple, active, declarative sentences continue to function as prototypes for the adult.

Attributes of prototypical sentences may play a role in sentence processing strategies across languages. As noted previously, the prototypical English sentence is thought to contain a NVN word order which corresponds to an animate actor, transitive verb, inanimate patient semantic arrangement in which the first noun/animate actor is also the topic of the sentence and the second noun/inanimate patient receives default stress. In three separate studies, Bates, MacWhinney, and their colleagues (Bates, McNew, MacWhinney, deVescovi, \& A. Smith, 1982; MacWhinney, Bates, \& Kliegl, 1984; MacWhinney, Pleh, \& Bates, 1985) tested the effect of independently varying these features in English, Italian, German, and Hungarian. In both English and Italian, word order and animacy were primary factors determining adults' choice of noun as subject-actor, with topic and stress less im- 
portant factors. In English, word order accounted for $51 \%$ of the variance, whereas animacy accounted for only $3 \%$. The results were reversed in Italian. In English, there was an interaction between word order and animacy; sentences in which there was a convergence of word order and animacy produced more choices than did word order alone and more choices than sentences in which word order and animacy were in conflict. Germans relied on animacy even more than did Americans. Hungarian children used animacy when other cues, such as case-marking, were not available. These results suggest that the factors determining prototypicality may combine in different ways in different languages.

Hypothesized attributes of prototypical sentence parts. Given a basic-level English sentence, some convergence of factors may combine to make some actors better choices than others and some verbs more prototypical. Analysis of within-case features has centered almost exclusively on the actor category, although there is occasional mention of the patient category. Although many of the descriptions overlap to some degree, authors have made no attempt to standardize their terminology. Also, there has been little psychological research to support most of the proposals.

There have been numerous speculations about the attributes of the actor category. Features suggested for a prototypical actor include: animacy (Bates \& MacWhinney, 1982; MacWhinney, 1982; Osgood \& Bock, 1977), humanness (Bates \& MacWhinney, 1982; Osgood \& Bock, 1977), motion (MacWhinney, 1982; Osgood \& Bock, 1977), ability to be a causal force (Cruse, 1973; MacWhinney, 1982), control over a situation, intention, responsibility, or volition (Bates \& MacWhinney, 1982; Cruse, 1973; Lakoff, 1977; Rhodes, 1977; VanOosten, 1977).

Certain verbs may be more typical than others. It has been suggested that prototypical verbs share the following attributes: intentionality; surface contact between the nouns (Bates \& MacWhinney, 1982; deVilliers, 1980; Hopper \& Thompson, 1980; Slobin, 1981); physical action resulting in a change of state in the object (Bates \& MacWhinney, 1982; deVilliers, 1980; Slobin, 1981); action on an existing object rather than creation; and punctual duration (deVilliers, 1980).

Obviously, this analysis of sentence parts is not totally independent from the analysis of the sentence as a whole. A nonprototypical exemplar of a case category may also affect prototypicality ratings of the entire sentence in ways that are yet to be determined. That is, prototypicality in linguistic categories depends on the discourse in which the category is embedded (Hopper \& Thompson, 1984), and context can restructure the representativeness distribution of the individual sentence parts (Roth \& Shoben, 1983). In addition, the attributes of each within-sentence component are not independent, but are correlated. The choice of a particular verb will affect with which noun it is paired. For example, a stative verb is more likely to be paired with an inanimate actor than is a verb that is high in action. Therefore, it is expected that the same nouns paired with different verbs or the same verbs paired with different nouns should show different prototypicality rankings.

It has thus been argued that the prototypical sentence (and the parts and attributes that define it) is critical for language acquisition (Slobin \& Bever, 1982) and that the attributes of sentence parts are critical for explaining processing differences across languages (Bates et al., 1982; MacWhinney et al., 1984, 1985). However, it has not been demonstrated that humans actually organize sentences in terms of prototypes. The current experiment investigated adult ratings of the prototypicality of various two-argument, transitive English sentences in order to determine if sentences exhibit the graded, goodness-ofexemplar distributions typical of other concepts. In other words, can knowledge of the cognitive processes underlying the formation of categories be generalized to language?

Using a technique developed by Rosch (1973), adults were asked to rate sentences based on their goodness of fit to the category transitive sentence. The sentences varied in the attributes of the various sentence parts, such as the animacy/inanimacy of the actor and/or patient and the prototypicality of the verb. Word order was the standard English SVO order. It was hypothesized that the sentences would show consistent rank orderings across subjects and a spread in ranking of sentences and sentence parts within categories, in the same manner as other natural categories. The weighting of the sentence-part attributes in determining subjects' ratings of the prototypicality of the sentences was then examined.

\section{METHOD}

\section{Subjects}

Subjects were 182 adult college students. They were recruited from nine advanced undergraduate- and graduate-level educational psychology courses. Seventy-four percent of the participants were 20 to 30 years of age and $22 \%$ were over 30 . The students were about equally distributed among junior, senior, and graduate class standings. Data from 148 students were used in the final analyses (see the discussion of Preliminary Analyses in the Results section for information on which subjects were eliminated).

\section{Materials}

Each student was given a form that contained a total of 32 test sentences. There were 8 sentences for each combination of animacy of the actors and patients: (animate/verb/inanimate, animate/verb/animate, inanimate/verb/animate, inanimate/verb/inanimate). Within each of the four major animacy combinations, different types of actors and patients were presented. Two of the animate beings were animals, and two were humans. Two of the inanimate objects were vehicles, and two were other types of objects. Four sentences of each animacy type (one for each subanimacy type) contained verbs that were judged independently by the experimenter and a second rater to be highly prototypical, and 4 contained verbs that were judged to be lower in prototypicality. The highly prototypical verbs were all judged to be high on an average of at least 3 of the 5 features identified by researchers as characteristic of prototypical verbs (high intention, punctual duration, surface contact 
between nouns, high physical activity, and highly perceptible change in location or state of the object). The verbs judged by the raters to be lower in prototypicality exhibited a mean of 2.5 or fewer features and were judged to have lesser amounts of some of the features they did exhibit (e.g., less surface contact, less activity). For example, the highly prototypical verb hit is high in intention, is punctual in duration, requires surface contact between the actor and patient, requires high physical activity, and usually involves a change in state or location of the patient. On the other hand, the less prototypical verb contact involves surface contact between nouns, but may involve no intention, a prolonged duration, little or no physical activity, and little or no change in state or location of the patient. Of course, the two categories of verbs are not really separate, but are at differing points on a continuum from more to less prototypical. Column 4 of Table 1 shows the mean number of features (out of a total of 5) for each of the high- and low-prototypicality verbs, as judged by the two raters.

A list of 512 different sentences was thus generated, such that each of the 32 verbs was used with every possible combination of animate and inanimate objects both within and across the four major animacy categories. This yielded 16 sets of 32 sentences. Four different noun pairs (e.g., two of the four were baker-cake and robbergun) for each subanimacy type (in this case, human animate/inanimate object) were each paired with 8 different verbs (4 highprototypicality and 4 low-prototypicality) across the 16 stimulus sets. Each noun pair thus occurred with half of the possible verbs.

Table 1

Rankings and Features of Hypothesized Highand Low-Prototypicality Verbs

Rankings*

\begin{tabular}{|c|c|c|c|}
\hline \multirow[b]{2}{*}{ Verb } & & & \multirow[b]{2}{*}{ Mean Number of Features $\dagger$} \\
\hline & Mean & Range & \\
\hline \multicolumn{4}{|c|}{ High-Hypothesized Prototypicality } \\
\hline clean & 4.28 & $1.33-6.00$ & 4.5 \\
\hline rinse & 4.13 & $2.44-6.11$ & 3.5 \\
\hline scrub & 4.83 & $2.33-6.43$ & 5 \\
\hline mark & 4.91 & $2.44-5.78$ & 4 \\
\hline dirty & 4.72 & $3.09-6.43$ & 3.5 \\
\hline lift & 3.75 & $1.44-5.70$ & 5 \\
\hline hoist & 3.80 & $1.44-6.14$ & 5 \\
\hline pick up & 3.71 & $1.22-6.43$ & 5 \\
\hline push & 3.94 & $1.14-6.22$ & 5 \\
\hline shove & 4.35 & $2.50-6.22$ & 5 \\
\hline hit & 3.61 & $1.75-5.55$ & 5 \\
\hline scratch & 4.00 & $2.00-6.22$ & 4 \\
\hline cut & 4.82 & $2.38-6.22$ & 5 \\
\hline nab & 4.40 & $2.00-5.71$ & 5 \\
\hline chase & 3.73 & $1.18-6.13$ & 3 \\
\hline squeeze & 4.99 & $2.13-6.71$ & 3.5 \\
\hline \multicolumn{4}{|c|}{ Low-Hypothesized Prototypicality } \\
\hline sprinkle & 4.36 & $2.33-5.50$ & 2.5 \\
\hline spot & 3.97 & $1.67-5.89$ & 2 \\
\hline soil & 4.33 & $2.44-6.43$ & 2.5 \\
\hline cover & 4.18 & $1.67-5.71$ & 2.5 \\
\hline occupy & 4.89 & $1.67-6.50$ & 1.5 \\
\hline shelter & 3.95 & $1.64-5.71$ & 1 \\
\hline support & 3.75 & $1.33-6.14$ & .5 \\
\hline hold & 3.76 & $2.13-5.00$ & 2 \\
\hline injure & 4.27 & $1.67-6.00$ & 2.5 \\
\hline rock & 4.10 & $2.00-6.00$ & 2.5 \\
\hline graze & 4.13 & $2.78-6.43$ & 2 \\
\hline tap & 4.54 & $2.25-6.25$ & 1.5 \\
\hline touch & 3.51 & $1.36-4.91$ & 2 \\
\hline contact & 4.94 & $3.55-5.88$ & .5 \\
\hline conceal & 3.25 & $1.63-6.00$ & 1.5 \\
\hline envelope & 5.12 & $4.00-6.25$ & 1.5 \\
\hline
\end{tabular}

*Based on rankings from all subjects. †Based on ratings of two judges
Each subject saw only one stimulus set of 32 sentences, that is, 32 verbs paired with 32 different noun pairs. Table 2 lists the 64 noun sets that were combined with the high- and low-prototypicality verbs to generate the sentences for the study.

In addition to the 32 experimental sentences in each set, two sentences that were judged by the author to be nongrammatical (syntactically or semantically inappropriate) were presented to the subjects, interspersed with the other sentences. They were included as a control to help weed out noncompliant subjects who might simply fill out the form randomly. Two of the experimental sentences were also repeated at the end of the form in order to check for withinsubject reliability.

The last part of the form consisted of data to be used for classificatory purposes: the age and year in school of the subject.

\section{Procedure}

Subjects were given verbal instructions adapted from Rosch (1973). They were told that the study "had to do with how people categorize things." Red and $d o g$ were used as examples of categories that had exemplars that could be ranked as to goodness of fit. Subjects were told that they would be asked to judge "how good an example of the category 'sentence' various instances" were. They were then presented with a list of sentences and asked to rate them on a 7-point scale from very good to very poor. In the results that follow, a lower rating thus indicates a better or more prototypical sentence.

\section{RESULTS}

Four major research questions were addressed via different sets of analyses. The first two questions examined the internal structure of the sentence and its parts: (1) Were rankings of the prototypicality of each sentence consistent across different subjects? (2) Across different sentences, was there a spread in rankings that was similar to that found in other research in which subjects ranked common objects? The last two questions examined the characteristics of the sentence parts and their effect on the "goodness" of the sentence as a whole: (3) Could the ranking of any particular sentence be predicted by the prototypicality of the verb and the animacy of the particular nouns with which it was paired? (4) Could the ranking of a particular noun combination be predicted by its animacy and by the verb with which it was paired?

\section{Preliminary Analyses}

Before beginning the major analyses, several preliminary analyses were performed to screen the data for outliers. First, rankings of the two nongrammatical sentences were examined. Contrary to expectations, subjects did not view the sentence "the tree eats the water" to be nongrammatical. The mean ranking of the sentence was 5.79, with a standard deviation of 1.35 . This was within the range of the means and standard deviations of the regular experimental sentences. The sentence was ranked between 1 and 4 by 38 subjects. This sentence, therefore, was not used for data screening purposes.

The sentence "The chair sits the woman" was viewed as nongrammatical by the majority of subjects. The mean ranking of this sentence was 6.59 and the standard deviation was .72. The sentence was ranked as a very poor one (between 5 and 7) by 167 students. The 15 subjects 
Table 2

Noun Pairs for the 16 Sentence Sets

\begin{tabular}{|c|c|c|c|c|c|}
\hline \multirow[b]{2}{*}{ Actor/Patient Noun Pair } & \multirow[b]{2}{*}{ Subanimacy } & \multirow[b]{2}{*}{ Mean } & \multirow[b]{2}{*}{ Range of Ranks } & \multicolumn{2}{|c|}{$\begin{array}{c}\text { Number of } \\
\text { Ranks } \\
\end{array}$} \\
\hline & & & & Good & Poor \\
\hline \multicolumn{6}{|c|}{ Animate/Inanimate } \\
\hline $\begin{array}{l}\text { paperboy/newspaper } \\
\text { custodian/mop } \\
\text { robber/gun } \\
\text { baker/cake }\end{array}$ & human/inanimate & $\begin{array}{l}3.86 \\
3.19 \\
3.37 \\
3.73\end{array}$ & $\begin{array}{l}2.14-6.33 \\
2.14-5.75 \\
1.75-5.57 \\
1.44-5.50\end{array}$ & $\begin{array}{l}3 \\
6 \\
5 \\
2\end{array}$ & $\begin{array}{l}5 \\
2 \\
3 \\
6\end{array}$ \\
\hline $\begin{array}{l}\text { engineer/train } \\
\text { worker/dumptruck } \\
\text { swimmer/rowboat } \\
\text { driver/racecar }\end{array}$ & human/vehicle & $\begin{array}{l}5.02 \\
4.38 \\
4.46 \\
4.60\end{array}$ & $\begin{array}{l}3.86-6.22 \\
2.67-6.43 \\
3.55-6.25 \\
3.30-5.50\end{array}$ & $\begin{array}{l}0 \\
2 \\
0 \\
2\end{array}$ & $\begin{array}{l}8 \\
6 \\
8 \\
6\end{array}$ \\
\hline $\begin{array}{l}\text { bird/window } \\
\text { cat/door } \\
\text { dog/bowl } \\
\text { squirrel/acorn }\end{array}$ & animal/inanimate & $\begin{array}{l}3.79 \\
4.00 \\
3.50 \\
3.07\end{array}$ & $\begin{array}{l}2.64-6.27 \\
2.00-6.00 \\
1.14-5.56 \\
1.44-4.73\end{array}$ & $\begin{array}{l}5 \\
4 \\
2 \\
5\end{array}$ & $\begin{array}{l}3 \\
4 \\
6 \\
3\end{array}$ \\
\hline $\begin{array}{l}\text { rabbit/snowmobile } \\
\text { elephant/circustruck } \\
\text { horse/wagon } \\
\text { lion/circustrain }\end{array}$ & animal/vehicle & $\begin{array}{l}4.55 \\
4.53 \\
4.36 \\
5.14\end{array}$ & $\begin{array}{l}2.75-6.14 \\
2.67-6.43 \\
2.29-6.43 \\
3.88-6.00\end{array}$ & $\begin{array}{l}2 \\
2 \\
1 \\
0\end{array}$ & $\begin{array}{l}6 \\
6 \\
7 \\
8\end{array}$ \\
\hline \multicolumn{6}{|c|}{ Animate/Animate } \\
\hline $\begin{array}{l}\text { nurse/baby } \\
\text { mom/infant } \\
\text { dad/girl } \\
\text { sheriff/bandit }\end{array}$ & human/human & $\begin{array}{l}2.86 \\
3.84 \\
3.84 \\
3.26\end{array}$ & $\begin{array}{l}1.22-5.33 \\
2.00-5.50 \\
2.13-5.67 \\
1.67-4.43\end{array}$ & $\begin{array}{l}5 \\
4 \\
3 \\
4\end{array}$ & $\begin{array}{l}3 \\
4 \\
5 \\
4\end{array}$ \\
\hline $\begin{array}{l}\text { boy/lamb } \\
\text { dogcatcher/dog } \\
\text { child/hamster } \\
\text { farmer/colt }\end{array}$ & human/animal & $\begin{array}{l}2.87 \\
2.70 \\
2.70 \\
2.92\end{array}$ & $\begin{array}{l}1.78-5.80 \\
1.18-4.44 \\
1.36-4.50 \\
1.44-5.50\end{array}$ & $\begin{array}{l}7 \\
6 \\
7 \\
6\end{array}$ & $\begin{array}{l}1 \\
2 \\
1 \\
2\end{array}$ \\
\hline $\begin{array}{l}\text { elephant/ringmaster } \\
\text { snake/hiker } \\
\text { skunk/camper } \\
\text { monkey/organgrinder }\end{array}$ & animal/human & $\begin{array}{l}3.70 \\
3.92 \\
3.97 \\
4.10\end{array}$ & $\begin{array}{l}2.20-5.36 \\
2.62-6.11 \\
2.44-5.88 \\
2.33-5.71\end{array}$ & $\begin{array}{l}5 \\
3 \\
4 \\
3\end{array}$ & $\begin{array}{l}3 \\
5 \\
4 \\
5\end{array}$ \\
\hline $\begin{array}{l}\text { duck/chicken } \\
\text { chipmunk/squirrel } \\
\text { pig/piglet } \\
\text { fawn/deer }\end{array}$ & animal/animal & $\begin{array}{l}4.42 \\
4.53 \\
3.34 \\
4.71\end{array}$ & $\begin{array}{l}3.44-5.88 \\
3.23-5.73 \\
2.13-4.67 \\
2.25-5.71\end{array}$ & $\begin{array}{l}1 \\
1 \\
4 \\
1\end{array}$ & $\begin{array}{l}7 \\
7 \\
4 \\
7\end{array}$ \\
\hline \multicolumn{6}{|c|}{ Inanimate/Animate } \\
\hline $\begin{array}{l}\text { ball/boy } \\
\text { wave/child } \\
\text { water/businessman } \\
\text { knife/boyscout }\end{array}$ & inanimate/human & $\begin{array}{l}5.39 \\
4.22 \\
5.36 \\
4.75\end{array}$ & $\begin{array}{l}4.33-6.22 \\
3.23-5.22 \\
4.63-6.56 \\
3.64-6.25\end{array}$ & $\begin{array}{l}0 \\
2 \\
0 \\
0\end{array}$ & $\begin{array}{l}8 \\
6 \\
8 \\
8\end{array}$ \\
\hline $\begin{array}{l}\text { mud/pig } \\
\text { box/gerbil } \\
\text { peanuts/chipmunk } \\
\text { door/kitten }\end{array}$ & inanimate/animal & $\begin{array}{l}5.00 \\
4.47 \\
5.18 \\
4.61\end{array}$ & $\begin{array}{l}3.40-6.22 \\
1.63-6.33 \\
3.10-6.71 \\
2.14-5.56\end{array}$ & $\begin{array}{l}1 \\
2 \\
1 \\
1\end{array}$ & $\begin{array}{l}7 \\
6 \\
7 \\
7\end{array}$ \\
\hline $\begin{array}{l}\text { sportscar/woman } \\
\text { bike/pedestrian } \\
\text { policecar/thief } \\
\text { firetruck/fireman }\end{array}$ & vehicle/human & $\begin{array}{l}4.47 \\
4.39 \\
4.31 \\
4.80\end{array}$ & $\begin{array}{l}2.78-5.86 \\
2.44-5.75 \\
3.38-5.71 \\
3.29-6.09\end{array}$ & $\begin{array}{l}2 \\
2 \\
2 \\
2\end{array}$ & $\begin{array}{l}6 \\
6 \\
6 \\
6\end{array}$ \\
\hline $\begin{array}{l}\text { car/puppy } \\
\text { circustruck/elephant } \\
\text { fishingboat/porpoise } \\
\text { wagon/sheep }\end{array}$ & vehicle/animal & $\begin{array}{l}4.72 \\
5.14 \\
4.97 \\
4.53\end{array}$ & $\begin{array}{l}1.75-6.13 \\
3.56-6.00 \\
3.14-6.11 \\
2.81-5.67\end{array}$ & $\begin{array}{l}2 \\
0 \\
1 \\
1\end{array}$ & $\begin{array}{l}6 \\
8 \\
7 \\
7\end{array}$ \\
\hline \multicolumn{6}{|c|}{ Inanimate/Inanimate } \\
\hline $\begin{array}{l}\text { bucket/water } \\
\text { fan/curtains } \\
\text { ketchup/necktie } \\
\text { hose/sidewalk }\end{array}$ & inanimate/inanimate & $\begin{array}{l}4.79 \\
4.79 \\
4.80 \\
4.54\end{array}$ & $\begin{array}{l}3.57-6.22 \\
3.36-6.14 \\
3.56-6.00 \\
2.25-5.18\end{array}$ & $\begin{array}{l}0 \\
1 \\
0 \\
1\end{array}$ & $\begin{array}{l}8 \\
7 \\
8 \\
7\end{array}$ \\
\hline $\begin{array}{l}\text { boulder/bike } \\
\text { hanger/airplane }\end{array}$ & inanimate/vehicle & $\begin{array}{l}4.37 \\
4.37\end{array}$ & $\begin{array}{l}3.11-5.50 \\
2.11-5.71\end{array}$ & $\begin{array}{l}2 \\
3\end{array}$ & $\begin{array}{l}6 \\
5\end{array}$ \\
\hline
\end{tabular}


Table 2 (Continued)

\begin{tabular}{lccccc} 
& & & \multicolumn{2}{c}{$\begin{array}{c}\text { Number of } \\
\text { Ranks }\end{array}$} \\
\cline { 3 - 6 } Actor/Patient Noun Pair & Subanimacy & Mean & Range of Ranks & Good & Poor \\
\hline & \multicolumn{2}{c}{ Animate/Inanimate } \\
surf/boat & 3.81 & $2.00-6.00$ & 3 & 5 \\
bridge/train & & 5.08 & $1.75-6.43$ & 1 & 7 \\
bulldozer/rock & vehicle/inanimate & 3.29 & $2.11-4.67$ & 5 & 3 \\
airplane/runway & & 4.21 & $1.67-5.60$ & 2 & 6 \\
tanker/beach & & 4.17 & $3.09-5.90$ & 2 & 6 \\
motorcycle/pole & & 4.43 & $1.78-5.67$ & 2 & 6 \\
bus/taxi & & 4.70 & $3.33-6.00$ & 1 & 7 \\
ferry/car & vehicle/vehicle & 4.14 & $3.33-5.80$ & 2 & 6 \\
van/sportscar & & 3.96 & $2.00-5.33$ & 1 & 7 \\
firetruck/policecar & & 4.99 & $3.11-6.50$ & 1 & 7 \\
\hline
\end{tabular}

who ranked this item between 1 and 4 were excluded from further analyses due to the possibility that they had inadvertently reversed the order of the ranking scale, or the possibility that they were responding randomly.

In addition, data from another 19 subjects were omitted because they failed to show a spread of at least 4 (out of 7) numbers in their rankings. Several subjects rapidly filled out the form, circling the same few numbers for all sentences. It is likely that these subjects were noncompliant.

Finally, the within-subjects agreement of each participant was monitored. These consistency ratings should be interpreted cautiously, because the form was only two pages in length and many subjects may have recalled their original ranking. Ninety percent of the subjects ranked identical items within two ranks of each other (e.g., 1 to 3 ). The proportion of agreement for subjects who had been omitted from the study on other grounds was .87 .

\section{Consistency of Rankings}

Intraclass correlation coefficients (ICC) were used to compute the consistency of rankings across subjects. This statistic is a measure of the proportion of variance accounted for in the dependent variable (in this case, subjects' rankings) by the independent variable (in this case, subjects). It is interpreted in the same way as $\omega^{2}$. Because subjects are considered to be a random variable, the intraclass correlation, rather than $\omega^{2}$, was calculated $(P . L$. Smith, 1982). The intraclass correlation reaches its maximum when scores (rankings) within each item are identical and they differ only between items (Kirk, 1982).

The ICC was estimated by the following equation (Shrout \& Fleiss, 1979):

$$
\frac{\mathrm{BMS}-\mathrm{EMS}}{\mathrm{BMS}+(k-1) \mathrm{EMS}+k(\mathrm{JMS}-\mathrm{EMS}) / n},
$$

where BMS is the between-item MS, EMS is the error MS, JMS is the between-judges (subjects) MS, $k$ is the number of judges, and $n$ is the number of items. This form of the intraclass correlation assumes that each of the $k$ randomly selected judges rates all $n$ items. The effect of treating judges as a random rather than a fixed variable is to reduce the value of the ICC, but it allows generalization to other populations of judges.

Separate ICCs were calculated for each of the 16 sets of sentences. They are shown in Table 3. The ICCs ranged from .16 to .47 with an average, across all 16 groups, of .31 .

\section{Spread in Rankings Across Items}

The 512 transitive sentences did show a spread in rankings similar to that found for noun categories in previous studies. Table 4 shows the 5 sentences with the mean highest and lowest rankings. The overall mean for all sentences was 4.24 , and the standard deviation was 1.09 . In contrast to previous studies of noun categories in which subjects showed a tendency to avoid the lower end of the rating scale, subjects in this study rated more sentences at the low end of the distribution than would be expected in a perfectly normal distribution.

\section{Effect of Animacy, Verb Prototypicality, and Sentence Set on Rankings}

A $(16 \times 4 \times 2)$ ANOVA was computed with the 16 different sets of sentences (composed of different verb and noun combinations) as a between-subjects variable, the

Table 3

Intraclass Correlations for Each Sentence Set

\begin{tabular}{cc}
\hline Sentence Set & Proportion of Variance Accounted for (ICC) \\
\hline 1 & .22 \\
2 & .41 \\
3 & .16 \\
4 & .25 \\
5 & .30 \\
6 & .23 \\
7 & .30 \\
8 & .32 \\
9 & .20 \\
10 & .36 \\
11 & .36 \\
12 & .29 \\
13 & .29 \\
14 & .33 \\
15 & .43 \\
16 & .47 \\
\hline
\end{tabular}

Note-ICC $=$ Intraclass correlation. 
Table 4

Sentences with Mean Highest, Average, and Lowest Rankings

\begin{tabular}{|c|c|c|}
\hline Sentence & Mean Ranking & $S D$ \\
\hline \multicolumn{3}{|l|}{ Highest } \\
\hline The dog pushes the bowl. & 1.14 & .38 \\
\hline The dogcatcher chases the dog. & 1.18 & .40 \\
\hline The nurse picks up the baby. & 1.22 & .44 \\
\hline The dog cleans the bowl. & 1.33 & .50 \\
\hline The nurse supports the baby. & 1.33 & .71 \\
\hline \multicolumn{3}{|c|}{ Average } \\
\hline The policecar picks up the thief. & 4.00 & 2.00 \\
\hline The baker supports the cake. & 4.00 & 2.00 \\
\hline The van shoves the sports car. & 4.00 & 2.00 \\
\hline The firetruck shelters the fireman. & 4.00 & 1.87 \\
\hline The squirrel envelopes the acorn. & 4.00 & 2.24 \\
\hline The horse pushes the wagon. & 4.00 & 1.87 \\
\hline \multicolumn{3}{|l|}{ Lowest } \\
\hline The bridge soils the train. & 6.43 & .77 \\
\hline The peanuts dirty the chipmunk. & 6.43 & .79 \\
\hline The firetruck occupies the policecar. & 6.50 & .76 \\
\hline The water squeezes the businessman. & 6.55 & .73 \\
\hline The peanuts squeeze the chipmunk. & 6.71 & .49 \\
\hline
\end{tabular}

four animacy types (AA, AI, II, IA) as the first withinsubjects variable and the two hypothesized levels of verb prototypicality (high or low) as the second within-subjects variable. The ANOVA summary table is shown in Table 5. The $d f$ in parentheses are the adjusted $d f$ for the Greenhouse-Geisser conservative $F$ test, and the $p$ level reflects this conservative procedure.

There was no main effect of sentence set, indicating that the different verb-and-noun combinations used to produce the 16 sets of sentences did not differ, on average.

Animacy. There was a main effect of animacy, accounting for $33 \%$ of the total variance. Table 6 shows 12 of the possible 14 contrasts that would be predicted if judges rated a sentence as good or poor compared with other sen- tences based solely on the animacy of one of the components. That is, if actor animacy alone were the basis for ranking sentences as good exemplars, then $\mathrm{AA}$ and $\mathrm{AI}$ sentences should be ranked lower than $\Pi$ and IA sentences (Contrasts 1-4). If patient animacy were the sole criterion, then AA and IA sentences should be ranked lower (better) than $\mathrm{AI}$ and II sentences (Contrasts 5-8). If patient inanimacy were the sole basis, then AI and II sentences should be ranked higher than AA or IA sentences (Contrasts 9-12). There is an additional set of four predictions that could be made if it were hypothesized that sentences with inanimate actors were always more prototypical. Because there is no basis in the literature for these predictions, they have not been included in the table. Note that several contrasts are duplicated on the basis of different judgment criteria (e.g., 4 and 11). There are also several contradictory contrasts in the three sets (e.g., 8 and 12), because actor or patient animacy alone does not produce subjects' prototypicality judgments; instead, the animacy of the sentence parts interacts.

The following results regarding the 12 contrasts were supported by post hoc Sheffé tests at the probability levels indicated in Column 2 of Table 6: When the animacy of the patient was held constant across sentences, sentence types containing animate actors were ranked higher than those containing inanimate actors (Contrasts 1 and 3 ). In sentence types in which patients were not equivalent, the animacy of the sentence actors took precedence over the animacy of the patients in determining subjects' judgments about the sentences (Contrasts 2 or 6 and 4 or 11), and Contrasts 7 and 10 were therefore not supported. Contrary to expectations that sentences with inanimate patients would be ranked as more prototypical than sentences with animate patients (Dixon, 1979; Slobin, 1981), Contrast 5 rather than Contrast 9 was supported. That is, when actors were both animate, then sentence types with animate

Table 5

ANOVA Summary Table

\begin{tabular}{lcrrrr}
\hline Source & $d f$ & Mean Square & \multicolumn{1}{c}{$F$} & $p$ & $R^{2}$ \\
\hline Sentence Set & 15 & 4.259 & .77 & .71 & .08 \\
Animacy & $3(2.82)$ & 69.059 & 106.14 & .0001 & .33 \\
Animacy at Set 1 & $3(2.82)$ & 4.972 & 7.64 & .0001 & \\
Animacy at Set 2 & $3(2.82)$ & 8.311 & 12.77 & .0001 & \\
Animacy at Set 3 & $3(2.82)$ & 1.406 & 2.16 & .096 & \\
Animacy at Set 4 & $3(2.82)$ & 9.508 & 14.61 & .0001 & \\
Animacy at Set 5 & $3(2.82)$ & 3.669 & 5.64 & .0011 & \\
Animacy at Set 6 & $3(2.82)$ & 7.172 & 11.02 & .0001 & \\
Animacy at Set 7 & $3(2.82)$ & 18.970 & 29.16 & .0001 & \\
Animacy at Set 8 & $3(2.82)$ & 2.397 & 3.68 & .012 \\
Animacy at Set 9 & $3(2.82)$ & 6.177 & 9.49 & .0001 & \\
Animacy at Set 10 & $3(2.82)$ & 14.483 & 22.26 & .0001 & \\
Animacy at Set 11 & $3(2.82)$ & 8.981 & 13.80 & .0001 & \\
Animacy at Set 12 & $3(2.82)$ & 2.533 & 3.89 & .011 & \\
Animacy at Set 13 & $3(2.82)$ & 5.364 & 8.25 & .0001 & \\
Animacy at Set 14 & $3(2.82)$ & 9.582 & 14.73 & .0001 & \\
Animacy at Set 15 & $3(2.82)$ & 3.723 & 5.73 & .001 & \\
Animacy at Set 16 & $3(2.82)$ & 12.600 & 19.36 & .0001 & \\
Error & $396(372.87)$ & .651 & & & \\
Verb Prototypicality & 1 & .460 & .87 & .353 & .004 \\
Verb at Set 1 & 1 & 2.000 & 3.77 & .054 & \\
Verb at Set 2 & 1 & .587 & 1.11 & .29 &
\end{tabular}


Table 5 (Continued)

\begin{tabular}{|c|c|c|c|c|c|}
\hline Source & $d f$ & Mean Square & $F$ & $p$ & $R^{2}$ \\
\hline Verb at Set 3 & 1 & .253 & .48 & .491 & \\
\hline Verb at Set 4 & 1 & 1.375 & 2.59 & .11 & \\
\hline Verb at Set 5 & 1 & 1.513 & 2.85 & .09 & \\
\hline Verb at Set 6 & 1 & .409 & .77 & .38 & \\
\hline Verb at Set 7 & 1 & .0003 & .06 & .81 & \\
\hline Verb at Set 8 & 1 & 4.013 & 7.56 & .007 & \\
\hline Verb at Set 9 & 1 & .313 & .58 & .444 & \\
\hline Verb at Set 10 & 1 & 5.500 & 10.36 & .002 & \\
\hline Verb at Set 11 & 1 & .176 & .33 & .56 & \\
\hline Verb at Set 12 & 1 & .002 & .03 & .86 & \\
\hline Verb at Set 13 & 1 & .286 & .54 & .46 & \\
\hline Verb at Set 14 & 1 & 1.806 & 3.40 & .067 & \\
\hline Verb at Set 15 & 1 & .362 & .68 & .41 & \\
\hline Verb at Set 16 & 1 & 9.389 & 17.69 & .0001 & \\
\hline Error & 132 & .531 & & & \\
\hline \multicolumn{6}{|l|}{ Animacy $\times$ Verb } \\
\hline Prototypicality & $3(2.98)$ & 10.072 & 16.77 & .0001 & .07 \\
\hline $\mathrm{AV}$ at Set 1 & $3(2.98)$ & .306 & .51 & .699 & \\
\hline $\mathrm{AV}$ at Set 2 & $3(2.98)$ & 8.270 & 13.77 & .001 & \\
\hline $\mathrm{AV}$ at Set 3 & $3(2.98)$ & 1.005 & 1.67 & .1725 & \\
\hline$A V$ at Set 4 & $3(2.98)$ & .962 & 1.60 & .19 & \\
\hline$A V$ at Set 5 & $3(2.98)$ & 1.915 & 3.19 & .024 & \\
\hline AV at Set 6 & $3(2.98)$ & 1.263 & 2.10 & .099 & \\
\hline AV at Set 7 & $3(2.98)$ & .422 & .70 & .55 & \\
\hline AV at Set 8 & $3(2.98)$ & 1.670 & 2.78 & .041 & \\
\hline AV at Set 9 & $3(2.98)$ & 1.195 & 1.99 & .115 & \\
\hline AV at Set 10 & $3(2.98)$ & 4.551 & 7.58 & .0001 & \\
\hline AV at Set 11 & $3(2.98)$ & .792 & 1.32 & .268 & \\
\hline $\mathrm{AV}$ at Set 12 & $3(2.98)$ & 10.070 & 16.76 & .0001 & \\
\hline AV at Set 13 & $3(2.98)$ & 2.688 & 4.47 & .004 & \\
\hline AV at Set 14 & $3(2.98)$ & 8.563 & 14.25 & .0001 & \\
\hline $\mathrm{AV}$ at Set 15 & $3(2.98)$ & 1.311 & 2.18 & .09 & \\
\hline $\mathrm{AV}$ at Set 16 & $3(2.98)$ & 5.155 & 8.58 & .0001 & \\
\hline Error & $396(393.57)$ & .601 & & & \\
\hline
\end{tabular}

Table 6

Hypotheses Concerning Ordering of Sentences with Animate/Inanimate Sentence Components

\begin{tabular}{|c|c|c|c|c|c|c|c|c|c|}
\hline \multirow[b]{3}{*}{ Hypothesis } & \multirow{3}{*}{$\begin{array}{c}\text { Level of } \\
\begin{array}{c}\text { Significance }(p) \\
\text { of Main }\end{array} \\
\text { Effect Contrasts }\end{array}$} & \multirow{2}{*}{\multicolumn{2}{|c|}{$\begin{array}{l}\text { Number of } \\
\text { Significant Animacy } \times \\
\text { Sentence Set Contrasts }\end{array}$}} & \multirow{2}{*}{\multicolumn{2}{|c|}{$\begin{array}{c}\text { Level of } \\
\text { Significance }(p) \\
\text { of Animacy } \times \\
\text { Verb Interac- } \\
\text { tion Contrasts } \\
\end{array}$}} & \multicolumn{4}{|c|}{$\begin{array}{l}\text { Number of Significant } \\
\text { Animacy } \times \text { Verb } \times \\
\text { Sentence Set Contrasts }\end{array}$} \\
\hline & & & & & & \multicolumn{2}{|c|}{ As Predicted } & \multicolumn{2}{|c|}{ Reversed } \\
\hline & & Predicted & Reversed & High* & Low* & High* & Low* & High* & Low* \\
\hline \multicolumn{10}{|c|}{ A $<$ I Actors } \\
\hline 1. $\mathrm{AA}<\mathrm{IA}$ & .01 & 12 & 0 & .01 & .01 & 4 & 2 & 0 & 0 \\
\hline 2. $\mathrm{AA}<\mathrm{II}$ & .01 & 8 & 0 & .01 & .01 & 4 & 0 & 0 & 0 \\
\hline 3. AI < II & .01 & 4 & 0 & .01 & n.s. & 2 & 0 & 0 & 0 \\
\hline 4. $\mathrm{AI}<\mathrm{IA}$ & .01 & 10 & 1 & .01 & n.s. & 5 & 0 & 0 & 1 \\
\hline \multicolumn{10}{|c|}{ A $<$ I Patients } \\
\hline $\begin{array}{l}\text { 5. } \mathrm{AA}<\mathrm{AI} \\
\text { 6. } \mathrm{AA}<\mathrm{II}\end{array}$ & $\begin{array}{c}.01 \\
\text { (See No. } 2 \text { above) }\end{array}$ & 6 & 0 & .01 & .05 & 1 & 0 & 0 & 0 \\
\hline 7. $\mathrm{IA}<\mathrm{AI}$ & $.01 \dagger$ & 1 & 10 & $.01 \dagger$ & n.s. & 0 & 1 & 5 & 0 \\
\hline 8. IA < II & $.01 \dagger$ & 2 & 4 & $.05 \dagger$ & n.s. & 0 & 2 & 1 & 2 \\
\hline \multicolumn{10}{|c|}{ I $<$ A Patients } \\
\hline 9. $\mathrm{AI}<\mathrm{AA}$ & $.01 \dagger$ & 0 & 6 & $.01 \dagger$ & $.05+$ & 0 & 0 & 1 & 0 \\
\hline 10. II $<\mathrm{AA}$ & $.01 \dagger$ & 0 & 8 & $.01 \dagger$ & $.01+$ & 0 & 0 & 4 & 0 \\
\hline 11. $\mathrm{AI}<\mathrm{IA}$ & (See No. 4 above) & & & & & & & & \\
\hline 12. II $<$ IA & .01 & 4 & 2 & .05 & n.s. & 1 & 2 & 0 & 2 \\
\hline
\end{tabular}

Note-Compare Nos. 4 and 7; Nos. 8 and 12; Nos. 5 and 9; Nos. 2 and 10. A = animate; I = inanimate. *"High" and "Low" refer to prototypicality of the verbs. $\nmid$ Probability is the significance level for the opposite prediction. 
Table 7

Mean Rankings for Each Sentence Set for Each Animacy Type

\begin{tabular}{ccccc}
\hline Sentence Set & AA & AI & II & IA \\
\hline 1 & 4.00 & 3.83 & 4.69 & 4.92 \\
2 & 3.42 & 3.44 & 4.153 & 4.85 \\
3 & 4.75 & 4.74 & 5.15 & 4.51 \\
4 & 3.83 & 3.79 & 4.54 & 5.17 \\
5 & 3.81 & 3.83 & 4.50 & 4.61 \\
6 & 3.39 & 3.92 & 4.01 & 4.77 \\
7 & 2.40 & 3.83 & 4.50 & 4.65 \\
8 & 4.24 & 3.79 & 3.98 & 4.59 \\
9 & 3.63 & 4.43 & 3.65 & 4.80 \\
10 & 3.53 & 5.14 & 5.00 & 3.83 \\
11 & 3.79 & 4.53 & 4.36 & 5.41 \\
12 & 3.83 & 3.95 & 4.72 & 4.28 \\
13 & 3.93 & 4.13 & 4.59 & 5.32 \\
14 & 3.25 & 3.95 & 4.02 & 5.02 \\
15 & 3.79 & 3.93 & 4.84 & 4.63 \\
16 & 3.18 & 4.07 & 4.08 & 5.22 \\
\hline
\end{tabular}

Note $-\mathrm{A}=$ Animate I $=$ Inanimate.

patients were ranked higher than those with inanimate patients. In comparing sentence types in which actors were both inanimate, the type with the inanimate patient was ranked higher than that with the animate patient (Contrast 12 rather than Contrast 8 ).

Animacy for each sentence set. Because the results would not be very interesting if they were due only to the idiosyncracies of particular sentences, a major question of interest was whether these contrasts held across all sentence sets (containing different verb-and-noun pairs). Therefore, the simple effects of animacy at each sentence set were tested. An additional $25 \%$ of the total variance was accounted for by the animacy $\times$ sentence set interaction, meaning that the simple main effects of animacy at each sentence set accounted for $58 \%$ of the total variance ( $33 \%$ for the main effect plus $25 \%$ for the interaction). As shown in Table 5, all means were significant using the Greenhouse-Geisser conservative $F$ test, with the exception of that of Group 3.

Using Sheffé post hoc contrasts, the 12 contrasts listed in Table 6 were then examined for each of the sentence sets. Comparison means for the sentence sets are shown in Table 7. Column 3 of Table 6 indicates the number of sentence sets supporting the prediction, and Column 4 indicates the number of sets showing results opposite the prediction. For all other sentence sets, the comparisons were nonsignificant. There were only six instances in which sentence sets reversed the findings from the overall ANOVA (compared to 68 instances in keeping with the overall findings). Thus, results suggest that findings regarding the effects of actor and patient animacy were general across many different exemplars of actors, patients, and verbs.

Verb prototypicality. Contrary to expectations, the hypothesized prototypicality of the verb (high vs. low) did not show a significant main effect (See Table 5). However, the simple main effects of verb were significant for several of the sentence sets, as shown in Table 5. There was also a significant animacy $\times$ verb interaction, as shown in Figure 1. Two contrasts in the figure were of interest. The first compared high- and lowprototypicality verbs for each animacy type. Inspection of the figure suggests that the verbs hypothesized to be of high prototypicality were ranked as better than those hypothesized to be of low prototypicality only for sentences with animate actors. What is a high-prototypicality verb for those sentences tends to be a low-prototypicality verb for sentences with inanimate patients. However, Scheffé post hoc analyses indicated that the contrast was significant only for IA sentences.

The second contrast of interest compared among animacy types for both verbs of high- and low-hypothesized prototypicality. The pattern of contrasts described previously for animacy main effects was basically supported for both high- and low-prototypicality verbs, as shown in Columns 5 and 6 of Table 6, although there were fewer significant effects for low-prototypicality verbs.

Similar results were obtained when the animacy $\times$ verb prototypicality interaction was examined for each sentence set. As shown in Table 5, the simple main effects for animacy $\times$ verb prototypicality, which accounted for .31 of the total variance, were significant for Sentence Sets $2,5,8,10,12,13,14$, and 16. Comparison between verbs of high- and low-hypothesized prototypicality for each animacy type indicated that sentences with highprototypicality verbs were ranked significantly higher than those with low-prototypicality verbs for AA sentences in Sentence Set 2 and II sentences in Set 12; this pattern was reversed with low-prototypicality verbs ranking higher than high-prototypicality verbs for IA sentences in Sentence Sets 10 and 12 and II sentences in Sets 14 and 16. High- and low-prototypicality verbs for each animacy type were also compared. The number of sets showing or reversing the predicted animacy contrasts is shown in Table 6 , Columns 7 through 10 . There were only six in-

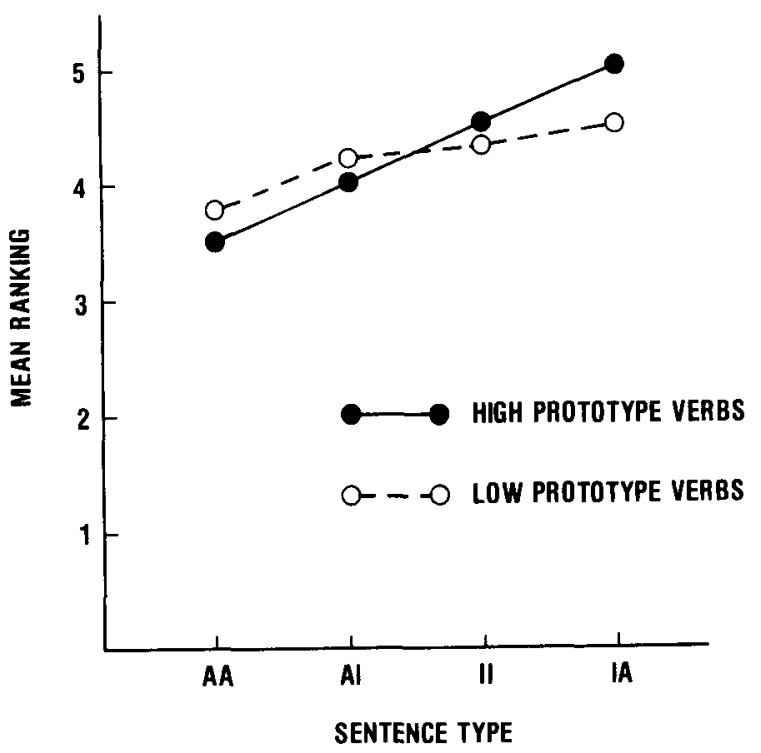

Figure 1. Sentence type animacy $\times$ prototypicality of verb inter. action. 
stances in which sentence sets reversed the findings from the overall ANOVA (compared to 33 instances in keeping with the overall findings).

In sum, there were consistent effects of both animacy and verb prototypicality both overall and for different noun and verb exemplars represented in different sentence sets. The particular verb-and-noun combinations used moderated those effects, making some high-prototypicality verbs higher than others and some particular animacy combinations better than others. The next analysis was an attempt to look at the effect of particular noun-pair combinations across different animacy types.

\section{Effect of Particular Noun-Pair Combinations}

Table 2 shows the mean rankings and the range of rankings for each noun pair (across the eight verbs that appeared with each noun pair), and the number of those rankings that were good $(<3.5)$ or poor $(>3.5)$. An ANOVA could not be computed for this data because different subjects contributed to the scores of each noun pair. For example, the pair workeridumptruck had been ranked by subjects who saw Sentence Sets 1, 2, 5, 8, 10, 13, and 15, whereas the pair baker/cake had been ranked by subjects who saw Sentence Sets $1,2,3,6,10,14$, and 16.

All noun-pair combinations showed a spread in rankings depending upon the verb with which they were paired. In most cases, the pattern of rankings seemed more dependent on the animacy of the noun pair than on the particular nouns used. The pattern of high and low rankings was quite similar across noun pairs within the same animacy category.

\section{DISCUSSION}

Rosch and her colleagues (1973, 1975; Rosch \& Mervis, 1975) have established that natural categories, such as colors or common nouns, are internally structured such that a best example is surrounded by other category members that are decreasingly similar to that prototypical central member. In this study, a nonobject category simple declarative sentence was examined to see if it exhibited the characteristics of other natural categories.

Adult subjects readily responded to the task of ranking sentences as good or poor sentences, just as they had done in previous research with other object categories. The 512 sentences used in this study formed an almost normal distribution of rankings, with fewer sentences ranked at both ends of the 7-point rating scale and more ranked in the middle. There was higher agreement as to which sentences constituted either very good or very poor sentences, and more variance in the middle of the distribution. These findings are consistent with those of McClosky and Glucksburg (1978), who found that subjects agreed on category membership of highly typical and atypical object exemplars, but showed more disagreement for objects that were intermediate in typicality.
Multiple factors, some of which have been identified in this study, contribute to subjects' judgments about the typicality of sentences. The students in this study, when questioned, seemed unaware of the factors that they were using to make their judgments; nonetheless, there was considerable agreement among subjects. The intraclass correlations found in this study (mean $=.31, N=16$ ) were comparable to those found by Tversky and Hemenway (1984) with object categories (mean $=.38, N=12$ ).

Subjects in previous studies tended to avoid the lower end of the rating scale. Students in the current study did the opposite. It is difficult to view any sentence that is listed on a rating form with no context as an excellent example of a sentence. In fact, it could be predicted that adding a context to the sentences used in this study would change their ratings and that varying the contexts would produce variations in ratings of the same sentence, just as varying the animacy of the nouns with which verbs were paired in this study changed the prototypicality of the verbs.

An analysis of the features used by subjects in categorizing sentences provides clues to the types of factors they use during sentence comprehension and production. In order to communicate, children must learn to produce sentences. In order to comprehend or produce sentences, they must learn what sentence parts are and how they go together. The task is made easier by the fact that there are prototypical actors, verbs, and patients that combine in prototypical ways to yield prototypical sentences. Working in the opposite direction, classification also allows children and adults to infer properties of sentences from their knowledge of the schema.

Transitive sentences in this study behaved like basiclevel categories composed of parts (actors, verbs, patients). Sentence parts, such as the actor, may be useful for distinguishing sentences from nonsentences, in the same way that a beak may be a useful part to distinguish birds from nonbirds. However, in normal discourse, it is assumed that everything that is heard is a sentence. It is therefore necessary to analyze the attributes or characteristics of sentence parts in the same way that it is necessary to analyze the type of beak to distinguish varieties of birds (Tversky \& Hemenway, 1984). The four sentence types, AA, AI, II, and IA, thus acted like subordinate categories, sharing parts such as actors, verbs, and patients, but differing on the attributes of the parts (animacy, degree of action of the verb, etc.). Attributes of the sentence parts are correlated, as they are for natural categories, allowing prediction of one attribute on the basis of another (e.g., high-prototypicality verb, animate actor). This also allows one to hear a sentence with unknown vocabulary and make inferences about the characteristics of its parts.

Results from the study indicate that characteristics of the parts, such as the animacy of the sentence participants, the prototypicality of the verbs, and possibly particular pairings of nouns, all play a role in subjects' judgments 
of the goodness of a sentence. Because of limitations in the available subject pool, all of these factors could not be varied independently in the current study, and further work with different sets of sentences is needed. Nevertheless, several important findings emerged.

First, Bates et al. (1982) found that animacy played only a small role in English in subjects' decisions about which noun in a sentence would be the subject-actor. However, current results suggest that the animacy of the sentence participants does play a significant role in subjects' judgments about sentences, when other factors are held constant. Overall, sentences containing animate actors are judged as being better than those containing inanimate actors, regardless of the animacy of the patient. In comparing sentence types in which both actors were animate, types with animate patients ranked higher than those with inanimate patients $(\mathrm{AA}<\mathrm{AI})$. However, in sentence types in which both actors were inanimate, inanimate patients took precedence over animate patients (II < IA). Because actors took precedence over patients, inanimate patients were also ranked higher than animate patients when they occurred with a combination of animate and inanimate actors, as in $\mathrm{AI}<\mathrm{IA}$ or $\mathrm{AA}<\mathrm{II}$.

Second, the finding that AA sentences were the best members of the category English transitive sentence may require a revision of the notion of the prototypical event schema (Slobin, 1981) and other linguistic formulations such as Dixon's (1979), which predicted that AI sentences would be prototypical. In fact, multiple factors go into subjects' judgments of prototypicality. AI sentences are sometimes rated higher than AA sentences, depending upon the prototypicality of the verb, the subanimacy of the nouns, and the particular noun pairs that are combined. However, with those factors constant, AA sentences were found to be more prototypical in the current study.

Third, verbs also played a role in subjects' sentence judgments. Verbs that had been designed to be highly prototypical (causing physical movement, direct contact, direct change in the patient, etc.) were judged to be higher than low-prototypicality verbs only for sentences with animate actors. Just as other object categories have correlated attributes, so do sentences: The prototypicality of the verb interacts directly with the animacy of the sentence participants. However, this finding may be partly a function of the way the study was designed. In order to have each verb occur in a sentence with every subanimacy type, generic verbs were chosen that may be less typical for use with certain animacy combinations. That is, some verbs in English are specific to a particular type of animacy combination and might be ranked very high in relation to other verbs within that category (e.g., "The human animate drove the car'). However, because verbs such as "to drive" cannot be used with other animacy combinations, it was not included in the sentences used in this study.

In conclusion, adult subjects perform a task to rank exemplars of a nonobject category, English declarative sen- tence, in a way that is consistent with their performance on other natural categories. Thus, the results of this research bear directly on the issue of what mechanisms underlie the comprehension and generation of language. Chomsky (1983) continues to argue that the language faculty is separate from other cognitive faculties. On the other hand, Anderson (1983) argues that the mechanisms underlying language use can be viewed as basically the same as those underlying other aspects of cognition. Data from the present experiment clearly support the position that similar categorization processes operate in both language and other cognitive domains.

\section{REFERENCES}

ANDERson, J. (1983). The architecture of cognition. Cambridge, MA: Harvard University Press.

BATES, E., \& MACWhinNeY, B. (1982). Functionalist approaches to grammar. In E. Wanner \& L. Gleitman (Eds.), Language acquisition: The state of the art. Cambridge, MA: Cambridge University Press.

Bates, E., McNew, S., MacWhinney, B., deVescovi, A., \& Smith, A. (1982). Functional constraints on sentence processing: A crosslinguistic study. Cognition, 11, 245-299.

BATES, E., \& SNYDER, L. (1982). The cognitive hypothesis in language development. In I. Uzgiris \& J. M. Hunt (Eds.), Research with scales of psychological development in infancy. Champaign-Urbana: University of Illinois Press.

Bornstein, M. (1984). A descriptive taxonomy of psychological categories used by infants. In C. Sophian (Ed.) Origins of cognitive skills. Hillsdale, NJ: Erlbaum.

CANTOR, N., \& Mischel, W. (1979). Prototypes in person perception. Advances in Experimental Social Psychology, 12, 3-52.

Cantor, N., Smith, E., French, R., \& Mezzich, J. (1980). Psychiatric diagnosis as prototype categorization. Journal of Abnormal Psychology, 89, 181-193.

CAREY, S. (1982). Semantic development, the state of the art. In E. Wanner \& L. Gleitman (Eds.), Language acquisition: The state of the art. Cambridge, MA: Cambridge University Press.

Chomsky, N. (1983). Noam Chomsky's views on the psychology of language and thought. In R. Rieber (Ed.), Dialogues on the psychology of language and thought. New York: Plenum Press.

CRUSE, D. (1973). Some thoughts on agentivity. Journal of Linguistics, 9, 11-23.

DEVILLIERS, J. (1980). The process of rule learning, a new look. In K. Nelson (Ed.), Children's language (Vol. 2). New York: Gardner Press.

Dixon, R. (1979). Ergativity. Language, 55, 59-138.

FoDOR, J. (1983). The modularity of mind. Cambridge, MA: MIT Press.

HOPPER, P., \& THOMPSON, S. (1980). Transitivity in grammar and discourse. Language, 56, 251-299.

HoPPER, P., \& THOMPSON, S. (1984). The discourse basis for lexical categories in universal grammar. Language, 60, 703-752.

KIRK, R. (1982). Experimental design. Belmont, CA: Brooks/Cole.

LAKOFF, G. (1977). Linguistic gestalts. Chicago Linguistic Society Papers, 13, 236-287.

MacWhinney, B. (1982). Basic syntactic processes. In S. Kuczaj (Ed.), Language development (Vol. 1). Hillsdale, NJ: Erlbaum.

MacWhinney, B., Bates, E., \& Kliegl, K. (1984). Cue validity and sentence interpretation in English, German, and Italian. Journal of Verbal Learning \& Verbal Behavior, 23, 127-150.

MacWhinney, B., Pleh, C., \& Bates, E. (1985). The development of sentence interpretation in Hungarian. Unpublished manuscript.

McClosky, M., \& GlucksBurg, S. (1978). Natural categories: Well defined or fuzzy sets? Memory \& Cognition, 6, 462-472.

Medin, D. (1983). Structural principles in categorization. In T. Tighe 
\& B. Shepp (Eds.), Perception, cognition, and development: Interactional development. Hillsdale, NJ: Erlbaum.

MEDIN, D., \& SMITH, E. (1984). Concepts and concept formation. Annual Review of Psychology, 35, 113-138.

Mervis, C. (1980). Category structure and the development of categorization. In R. Spiro, B. Bruce, \& W. Brewer (Eds.), Theoretical issues in reading comprehension. Hillsdale, $\mathrm{NJ}$ : Erlbaum.

Mervis, C., Medin, D., \& Rosch, E. (1984). Salience of correlated attributes. Journal of Experimental Psychology: General, 113 194-197.

Mervis, C., \& Rosch, E. (1981). Categorization of natural objects. Annual Review of Psychology, 32, 89-115.

Oscoon, C., \& Bock, J. (1977). Salience and sentencing: Some production principles. In S. Rosenberg (Ed.), Sentence production: Developments in research and theory. Hillsdale, NJ: Erlbaum.

RHODES, R. (1977). Semantics in a relational grammar. Chicago Linguistic Society Papers, 13, 503-514.

Rosch, E. (1973). On the internal structure of perceptual and semantic categories. In T. Moore (Ed.), Cognitive development and the acquisition of language. New York: Academic Press.

Rosch, E. (1975). Cognitive reference points. Cognitive Psychology, 7, 532-547.

Rosch, E., MERvis, C. (1975). Family resemblances: Studies in the internal structure of categories. Cognitive Psychology, 7, 573-609.

Rosch, E., Mervis, C., Gray, W., Johnson, D., \& Boyes-Braem, P. (1976). Basic objects in natural categories. Cognitive Psychology, 8 $382-439$.
Roth, E., \& Shoben, E. (1983). The effect of context on the structure of categories. Cognitive Psychology, 15, 346-378.

SCHLESINGER, I. (1982). Steps to language. Hillsdale, NJ: Erlbaum. SHROUT, P., \& FLEISS, J. (1979). Intraclass correlations: Uses in assessing rater reliability. Psychological Bulletin, 86, 420-428.

SLobin, D. (1981). The origin of grammatical encoding of events. In W. Deutsch (Ed.), The child's construction of language. New York: Academic Press.

SLOBIN, D., Bever, T. (1982). Children develop canonical sentence schemas: A cross-linguistic study of word order and inflections. Cognition, 12, 229-265.

Smith, E., \& Medin, D. (1981). Categories and concepts. Cambridge, MA: Harvard University Press.

SMITH, P. L. (1982). Measures of variance accounted for: Theory and practice. In G. Keren (Ed.), Statistical and methodological issues in psychology and social sciences research. Hillsdale, NJ; Erlbaum.

TALMY, L. (1977). Rubber sheet cognition in language. Chicago Linguistic Society Papers, 13, 612-628.

Tversky, B., \& Hemenway, K. (1983). Categories of environmental scenes. Cognitive Psychology, 15, 121-149.

TVERSKY, B., \& HeMENWAY, K. (1984). Objects, parts, and categories. Journal of Experimental Psychology: General, 113, 169-193.

VanOosten, J. (1977). Subjects and agenthood in English. Chicago Linguistic Society Papers, 13, 459-471.

(Manuscript received August 6, 1985; revision accepted for publication February $27,1986$. 